\title{
Dynamic Modeling and Simulation of a Thermoelectric-Solar Hybrid Energy System Using an Inverse Dynamic Analysis Input Shaper
}

\author{
A. M. Yusop, R. Mohamed, A. Ayob, and A. Mohamed \\ Department of Electrical, Electronic and Systems Engineering, Faculty of Engineering and Built Environment, \\ Universiti Kebangsaan Malaysia (UKM), 43600 Bangi, Selangor, Malaysia
}

Correspondence should be addressed to A. M. Yusop; azdiana@utem.edu.my

Received 8 February 2014; Accepted 27 May 2014; Published 24 June 2014

Academic Editor: Mingcong Deng

Copyright (C) 2014 A. M. Yusop et al. This is an open access article distributed under the Creative Commons Attribution License, which permits unrestricted use, distribution, and reproduction in any medium, provided the original work is properly cited.

\begin{abstract}
This study presents the behavioral model of thermal temperature and power generation of a thermoelectric-solar hybrid energy system exposed to dynamic transient sources. In the development of thermoelectric-solar hybrid energy system, studies have focused on the regulation of both systems separately. In practice, a separate control system affects hardware pricing. In this study, an inverse dynamic analysis shaping technique based on exponential function is applied to a solar array (SA) to stabilize output voltage before this technique is combined with a thermoelectric module (TEM). This method can be used to estimate the maximum power point of the hybrid system by initially shaping the input voltage of SA. The behavior of the overall system can be estimated by controlling the behavior of SA, such that SA can follow the output voltage of TEM as the time constant of TEM is greater than that of SA. Moreover, by employing a continuous and differentiable function, the acquired output behavior of the hybrid system can be attained. Data showing the model is obtained from current experiments with predicted values of temperature, internal resistance, and current attributes of TEM. The simulation results show that the proposed input shaper can be used to trigger the output voltage of SA to follow the TEM behavior under transient conditions.
\end{abstract}

\section{Introduction}

Issues involving the continuous increase in oil price and environmental awareness have attracted extensive research interests for renewable energy power generation. Solar energy, hydro energy, nuclear energy, and wind energy are commonly used to produce electricity, thereby reducing carbon dioxide gas emissions [1]. Solar energy is one of the most frequently used types of renewable energy; however, solar energy should be stored for future use because sunlight is the only source of this type of energy; as such, the availability of this type of energy varies with time.

The conversion of solar energy into electricity can be conducted by applying photovoltaic technology. This technology has received remarkable progress since 1839 [2]. However, solar array (SA) fails to function at certain times of the day; for this reason, researchers have been prompted to improve SA efficiency. Although efficiency can be further enhanced, the improvement of SA performance has been impeded because of heat dissipation and development costs $[2,3]$. TEM is a preferable device to overcome the current problems on photovoltaics, in which this solid state device is able to transform waste thermal energy into electricity when thermal gradient is present between two junctions [4]. This device can be considered as one of the most efficient candidates used for energy conversion because this energy produces no waste matter during conversion. However, TEM cannot operate individually as a beneficial energy converter. In several studies, SAs and TEMs have been combined to develop a hybrid energy system that utilizes the benefits of both technologies [1,5-7].

SA and TEM are nonlinear devices with output characteristics depending permanently on external substantial effects, such as maximum power point that should be tracked efficiently [5]. In a previous study [1], a hybrid energy system comprised a dual Ćuk converter to lodge power for multiple 
inputs; this hybrid is suitable for a grid connected system. The proposed method in another study [5] considers an optimal circuit design to control solar energy power, in which SA and TEM are arranged in a master/slave mode. Using an optimal circuit, a controller is developed to predict the maximum power point and can control both systems simultaneously. An extension hybrid TEM-SA system with liquid cooling is assembled to increase the efficiency of current hybrid systems $[6,7]$.

This study aims to conduct a dynamic analysis of a hybrid TEM-SA configuration by using MATLAB with extra identification to increase the efficiency of the existing hybrid TEM-SA and to reduce the energy consumption of the system. Previous studies have also focused on an MPPTdesigned circuit in hybrid energy systems. As such, this MPPT circuit should be designed separately for both systems because various maximum power points are obtained for different systems. Although an optimal controller circuit is designed to control SA behavior [5], this circuit uses passive element devices, together with a digital signal processor. One of the drawbacks of this technique is the increased power consumption of the power circuit because of digital computation. For this reason, a feedforward controller with regard to input shaping scheme is introduced in this study. Input shaping is commonly used controller technique to control the vibration of moving or flexible systems $[8,9]$. This technique is also used to control the settling time of a positioning system from one value to another [10]. Studies have also focused on this field since the 1980s. In input shaping, several approaches, including "posicast" control [11, 12], impulse shaping [13], command shaping [14], zero vibration derivative technique (ZVD) [15], and extra insensitive technique [16], are used. In a previous study [17], a three-step (TS) input shaping technique was applied, in which three-impulse shaping is provided with positive and negative shapers. In this technique, this new shaper extends the current zero vibration derivative (ZVD) technique to a generalized TS shaper method; this improved technique can function appropriately in any dynamic model. In these methods, input function should be computed and output behavior mainly depends on the given input. An inverse dynamic analysis type of input shaper has been proposed by Piazzi and Visioli [18] via employing polynomial function as the acquired output function. Although the ideas of Piazzi and Visioli are interesting and useful, they need to switch the polynomial function into another function because of the erratic behaviour of this function after attaining the end point. This argument is accepted by all critics. For instance, Iravani and Sahinkaya in [19] hold that the switching will bring in the discontinuity in both the first and second derivatives of the function which leads to the unstable output behaviour of the applied system. Particularly, Zhao et al. in their continuous works in [20-22] concentrate on the stability problem in arbitrary switching. The addressed problem is solved by introducing multiple copositive types LyapunovKrasovskii functional. Additionally, the multiple copositive types Lyapunov-Krasovskii functional is reduced to the common copositive type Lyapunov-Krasovskii functional. In here, they consider applying the suggested method to the feedback controller. Another method regarding the switching signal is the dwell time method which has received increasing attention since this method is able to stabilize the system when the dwell time is adequately high; see [23-25].

Moreover, the idea from Piazzi and Visioli has been extended in previous studies $[8,9,19,26]$ using exponential function which has been proven to overcome the limitation of the polynomial function. On the whole, this inversion scheme is based on the feedforward control technique which does not need feedback measurements. As a matter of fact, in SA design, the occurrence of feedback measurement to obtain the maximum power tends to increase the energy consumption of the overall system.

In this study, an inverse dynamic analysis type of an input shaper based on exponential function was added to the SA model to control the input behavior of a photovoltaic array. The controller part in SA is designed so that the SA is able to collect solar energy throughout the day. More importantly, the voltage and intensity formed by the SA can be controlled consecutively to function at the highest operating point. With this method, the energy consumption of the system is further minimized. Significant efforts have been devoted to the development of this input shaper, in which the input shaper is designed according to the acquired output behavior of the hybrid energy system. In addition, the inverse dynamic type input shaper can be established by using built-in control blocks, which can be further combined using SimPowerSystem tools for the MPPT circuit development.

\section{Modeling of the Thermoelectric Module and Solar Array}

The models of TEM and SA modules are designed separately by inserting the corresponding numbers of modules in series or parallel before both systems are combined. As the time constant of TEM is evidently greater than that of SA, TEM is designed to function as the master and SA is designed as the slave.

2.1. Modeling of the Thermoelectric Module. In this model, TEM functions under a dynamic condition, in which the temperature of the cold side is maintained for natural cooling to produce a dynamic response because many studies have focused on the analysis of a steady state behavior, which only involves constant temperature [4]. In practice, the temperature of TEM input fluctuates with time.

To obtain the heat model of TEM, we considered several effects, including thermal conduction, Joule, Peltier, Seebeck, and Thomson. However, Thomson effect is ignored because such effect is very small.

To ensure that heat is distributed equally at both junctions, we should ensure that TEM exhibits high thermal conductivity. Thermal conductivity is expressed according to Fourier process with heat transfer, $Q_{\mathrm{tc}}$, as follows:

$$
Q_{\mathrm{tc}}=-\Delta T \kappa_{\mathrm{tc}}
$$

where $\kappa_{\mathrm{tc}}$ is the thermal conductivity and $\Delta T$ is the difference between sides of high and low temperatures. Joule effect is 
produced internally when electrical current, $I$, flows across a thermoelectric leg. This effect is observed in both sides at different temperatures but with the same amount of energy as follows:

$$
Q_{\text {joule }}=I^{2} R
$$

where $R$ is the electrical resistance. Peltier effect is observed when electrical current flows through two different junctions and the total heat transfer is expressed as follows:

$$
Q_{\text {peltier }}=\alpha \Delta T I,
$$

where $\alpha$ is the Seebeck coefficient of the TEG. Seebeck effect shows that the temperature difference between two different electrical conductors or semiconductors produces a voltage difference between two junctions. Seebeck coefficient is also defined as follows:

$$
\alpha=\frac{V}{\Delta T} .
$$

In the design of a TEM at specific thermal flow and temperature, the maximum power point should be obtained. If load resistance is equal to the internal resistance of TEM, output power is equal to the peak value. Equation (5) shows the energy balance equations used for steady state analysis at hot and cold junctions of TEM as follows:

$$
\begin{aligned}
Q_{h} & =\alpha T_{h} I-\kappa_{\mathrm{tc}} \Delta T-0.5 I^{2} R, \\
Q_{c} & =\alpha T_{c} I-\kappa_{\mathrm{tc}} \Delta T+0.5 I^{2} R .
\end{aligned}
$$

To develop a good TEM, a high Seebeck coefficient, together with low electrical resistance and low thermal conductivity, should be provided [27]. In the figure of merit, $Z$ relates this statement and is expressed as follows:

$$
Z=\frac{\alpha^{2}}{R \kappa_{\mathrm{tc}}} .
$$

In terms of the electrical properties of TEM, the following parameters are frequently used to specify TEM characteristics: $T_{h}$, temperature in the hot side; $T_{c}$, temperature in the cold side; $W_{m}$, the power at the load resistance, $R_{L}$, internal resistance, $R$, where $\left(R_{L}=R\right)$; and $V_{m}$, load voltage. Electrical resistance and Seebeck coefficient are expressed as follows:

$$
\begin{gathered}
R=R_{L}=\frac{V_{m}^{2}}{W_{m}}, \\
\alpha=\frac{2 V_{m}}{\Delta T} .
\end{gathered}
$$

The following relationship shows that load resistance can be varied in proportion to internal resistance. Consider

$$
R_{L}=m R
$$

where $m$ is the ratio between load resistance and internal resistance. In (4), $I$ is expressed as follows:

$$
I=\frac{\alpha \Delta T}{(1+m) R}
$$

TABLE 1: Specification of TEM (TEP1-12656-0.6).

\begin{tabular}{lc}
\hline Specifications & Values \\
\hline Hot side temperature $\left({ }^{\circ} \mathrm{C}\right)$ & 300 \\
Cold side temperature $\left({ }^{\circ} \mathrm{C}\right)$ & 30 \\
Open circuit voltage $(\mathrm{V})$ & 8.4 \\
Matched load resistance $(\Omega)$ & 1.2 \\
Matched load output voltage $(\mathrm{V})$ & 4.2 \\
Matched load output current $(\mathrm{A})$ & 3.4 \\
Matched load output power $(\mathrm{W})$ & 14.6 \\
Heat flow across the module $(\mathrm{W})$ & $\approx 365$ \\
Heat flow density $\left(\mathrm{W} \mathrm{cm}^{-2}\right)$ & $\approx 11.6$ \\
AC resistance measured at $27^{\circ} \mathrm{C}$ and $1000 \mathrm{~Hz}(\Omega)$ & $0.5-0.7$ \\
\hline
\end{tabular}

The maximum output power at matching load, $R_{L}=R$, is obtained before any controller or MPPT circuit is designed. The maximum current of TEM is the short-circuit current at zero load voltage, $V_{L}=0$, which is expressed as follows:

$$
I_{\text {short-ckt }}=2 I_{m}=\frac{2 W_{m}}{V_{m}} .
$$

According to Ohm's Law and the resulting equations (9) and (10), the TEM voltage can then be obtained as follows:

$$
V=-R\left(I-I_{\text {short-ckt }}\right) \text {. }
$$

The TEM model TEP1-12656-0.6 (Thermonamic) is used in this model, in which steady-state analysis is initially conducted to verify the electrical parameters of the TEM model. The specifications of the TEG module (TEP1-12656$0.6)$ are listed in Table 1 and the parameters for steady state condition verification are obtained by applying equations (1) to (6). The value of the model parameter under steady state analysis can be calculated as follows; $\alpha=0.031 \mathrm{~V} / \mathrm{K}, R=$ $1.2 \Omega, \kappa_{\mathrm{tc}}=20.85 \mathrm{~W} / \mathrm{K}$, and $Z=3.869 \times 10^{-5} \mathrm{~K}^{-1}$.

The TEM model is implemented using MATLAB/SIMULINK as shown in Figure 1. The inputs of the model include the sides with cold and hot temperatures of the TEM configuration.

2.2. Modeling of Solar Array. The characteristics of SA depend on the solar radiation and temperature of the SA surface. As solar radiation is increased, power produced by $\mathrm{SA}$ is increased; by comparison, an increase in temperature reduces output power. To attain the highest output power, we should reduce the temperature of SA. The equivalent circuit of the solar cell is shown in Figure 2.

A group of solar cells is then combined in series-parallel configuration to structure as an SA. In Figure 2, cell photocurrent, $I_{\mathrm{PH}}$, functions as current source, $R_{\mathrm{SH}}$ is the internal shunt resistance of the cell, and $R_{S}$ is the series resistance of the cell. In a previous study [28], SA can be modeled mathematically using (12) to (15). The $I-V$ characteristic of $\mathrm{SA}$ is represented as follows:

$$
I_{\mathrm{SA}}=N_{P} I_{\mathrm{PH}}-N_{P} I_{\mathrm{SAT}}\left[\exp \left\{\frac{q\left(V_{\mathrm{SA}}+I_{\mathrm{SA}} R_{S}\right)}{N_{S} A k T}\right\}-1\right],
$$




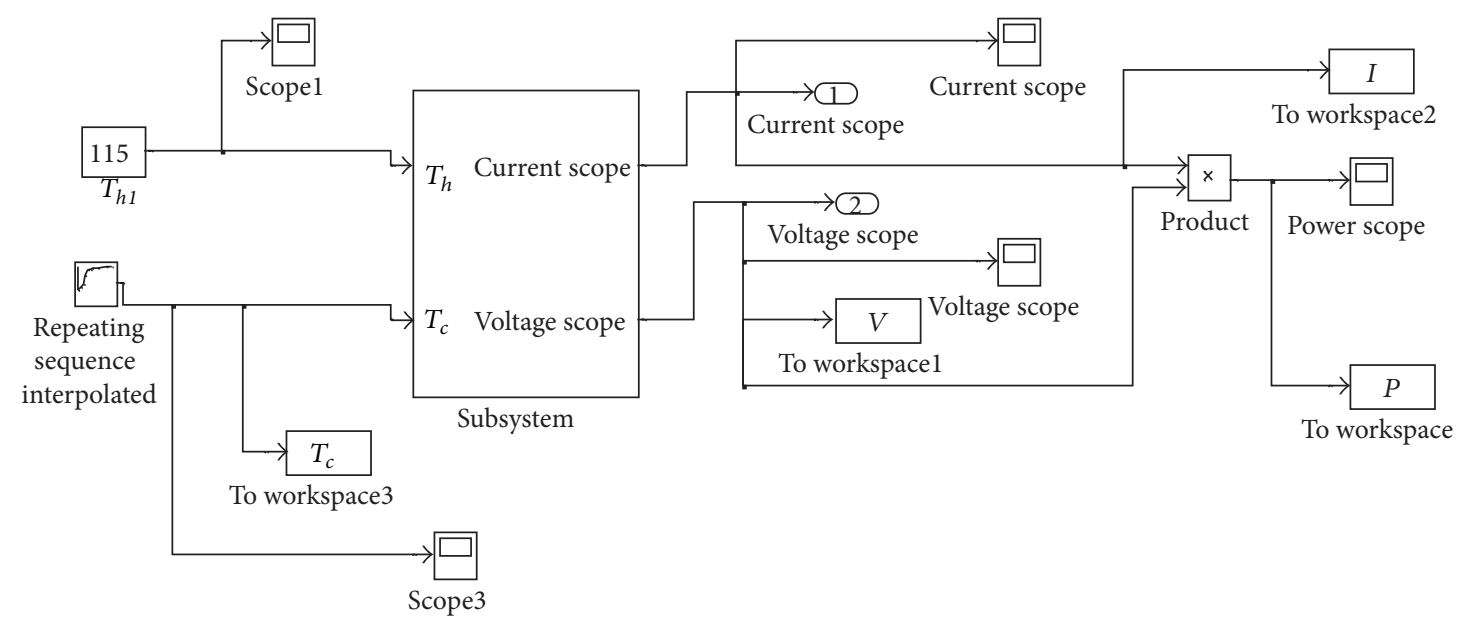

FIGURE 1: TEM block model as applied in MATLAB.

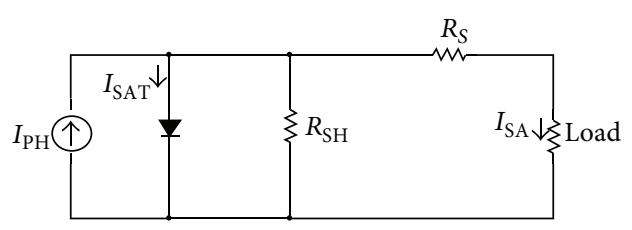

FIGURE 2: Equivalent circuit of a solar cell.

TABle 2: Factor of $A$ depends on PV technology [31].

\begin{tabular}{lc}
\hline Technology & Value of $A$ \\
\hline Si-mono & 1.2 \\
Si-poly & 1.3 \\
a-Si:H & 1.8 \\
a-Si:H tandem & 3.3 \\
a-Si:H triple & 5 \\
CdTe & 1.5 \\
CIS & 1.5 \\
AsGa & 1.3 \\
\hline
\end{tabular}

where $I_{\mathrm{SA}}$ and $V_{\mathrm{SA}}$ are the output current and the output voltage of SA, respectively, $I_{\mathrm{SAT}}$ is the saturation current that varies with cell temperature, $N_{P}$ and $N_{S}$ are the total number of cells in parallel and in series, respectively, $q$ is the charge of an electron $\left(1.6 \times 10^{-19} \mathrm{C}\right), R_{S}$ is the series resistance, $A$ is the ideality factor of a p-n junction, which depends on the photovoltaic voltage (PV) technology (Table 2), $k$ is Boltzmann constant $\left(1.3805 \times 10^{-23} \mathrm{~J} / \mathrm{K}\right)$, and $T$ is the module operating temperature.

$I_{\mathrm{PH}}$ is directly proportional to solar insolation and is defined as follows:

$$
I_{\mathrm{PH}}=\left[I_{\mathrm{SC}}+K_{i}(T-298)\right] \times \frac{\lambda}{1000},
$$

where $I_{\mathrm{SC}}$ is the short circuit current, $K_{i}$ is the short circuit current coefficient at $I_{\mathrm{SC}}$, and $\lambda$ is the PV module illumination.
TABLE 3: Specification of solar module (SR10-36).

\begin{tabular}{lc}
\hline Specifications & Values \\
\hline Maximum power (W) & 10 \\
Maximum power voltage (V) & 17 \\
Maximum power current (A) & 0.59 \\
Open circuit voltage (V) & 21.6 \\
Short circuit current (A) & 0.64 \\
\hline
\end{tabular}

The module saturation current, which keeps changes with cell temperature, is expressed as follows:

$$
I_{\mathrm{SAT}}=I_{\mathrm{RS}}\left(\frac{T}{T_{\text {ref }}}\right)^{3} \exp \left[\frac{q \times E_{g}}{A k}\left(\frac{1}{T_{\text {ref }}}-\frac{1}{T}\right)\right],
$$

where $I_{\mathrm{RS}}$ is the reverse saturation current, $T_{\text {ref }}$ is the reference temperature, and $E_{g}$ is the band gap for silicon $(1.1 \mathrm{eV}) . I_{\mathrm{RS}}$ in (14) is expressed as follows:

$$
I_{\mathrm{RS}}=\frac{I_{\mathrm{SC}}}{\left[\exp \left(q \times V_{\mathrm{OC}} / N_{s} k A T\right)-1\right]},
$$

where $V_{\mathrm{OC}}$ is the open circuit voltage.

Solar module SR10-36 from Raloss is used as the SA model in this design. The details of the electrical characteristics of the module are listed in Table 3 and this specification is modeled using MATLAB/SIMULINK (Figure 3).

The $I-V$ and $P-V$ characteristics of SA depend on terminal operating voltage, insolation, and surface temperature. These characteristics are obtained by varying insolation at constant temperature or varying temperature at constant insolation. The polycrystalline silicon solar cells chosen in this SA yield low power consumption and entail less production costs, which likely increase the total performance of development [6].

\section{Input Shaper for the Hybrid Energy System}

The thermoelectric-solar hybrid energy system is implemented in the SIMULINK/MATLAB (Figure 4). The input 


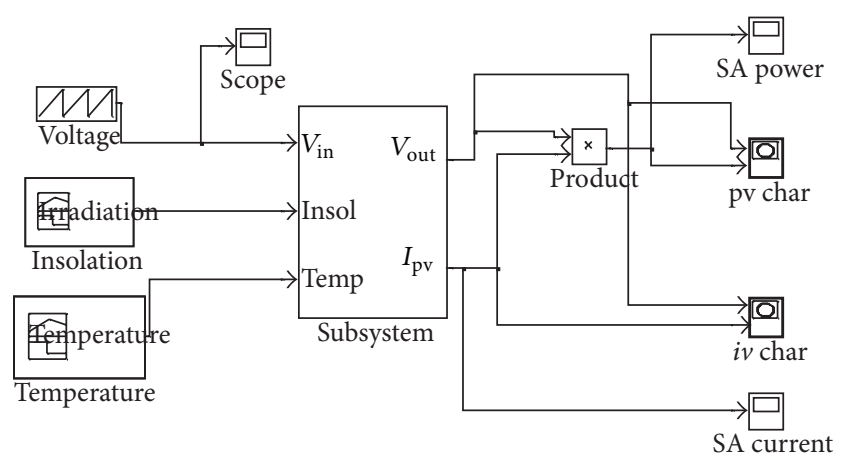

Figure 3: SA block model applied in MATLAB.

shaper used in inverse dynamic analysis is added at the input of SA to control the output characteristic of SA, such that the TEM characteristic is observed. This system comprises six pieces of TEM, two pieces of SA, and an input shaper. The TEM is connected in series and thermally in parallel, whereas both SAs are connected electrically in parallel to increase the output power of an individual system before these SAs are combined to perform a hybrid energy system.

SA exhibits a nonlinear characteristic because the output characteristics depend on external factors, such as temperature and sunlight irradiation. Considering these factors, we should accurately track the maximum power point of this device. In this study, the inverse dynamic analysis exponential type of input shaper is used to simulate the input voltage of SA before it is connected to the other parts of the SA subsystem. This input shaper also aims to reverse the control method by initially indicating the system output function and then deriving the input form. In this way, the form of output characteristics can be selected based on system limitations. In the present study, the output function should be used with only one parameter to control the characteristics from the final point onwards; as a result, a simple input function is obtained. The particular constraint of output form determines output power along with controlling the system limitations. Figure 5 shows the $I-V$ and $P-V$ characteristics of a solar cell. In particular, power curve contains a maximum power point (MPP). In this study, the MPP voltage, $V_{\mathrm{MPP}}$, is less than the open circuit voltage, $V_{\mathrm{OC}}$, and $I_{\mathrm{MPP}}$ is lower than $I_{\mathrm{SC}}$. At MPP, current and voltage exhibit almost the same relation to irradiance and temperature changes.

The power behavior of SA is constant from an initial time point to a specific end point until power decreases drastically to a negative value. For the selected SA model, power decreases to a large negative value, which likely results in an overall power curve to follow SA behavior. As a result, TEM automatically follows the SA behavior, which is impractical to obtain the maximum power of the overall system, when an SA diagram and a TEM block diagram are combined to form a hybrid system.

3.1. Inverse Dynamic. The inverse dynamic is only applied to the voltage equation of the SA since the current behaviour automatically changed when the voltage function is changed.
As mentioned earlier, the SA power needs to be set to follow the TEM behaviour. Before designing any input shaper, the form of the target output waveform needs to be confirmed first. In the simulation, the SA input voltage is set to be a sawtooth signal and based on Weisstein [30] this signal is represented as follows:

$$
V_{\mathrm{SA}}(x)=A \operatorname{frac}\left(\frac{x}{T}+\phi\right),
$$

where $\operatorname{frac}(x)$ is the fractional part $\operatorname{frac}(x) \equiv x-\lfloor x\rfloor, A$ is the amplitude, $T$ is the period of the wave, and $\phi$ is its phase. The output voltage of the SA is equivalent to the input voltage. From (16), it shows that the SA voltage form is a first order system.

The system transfer function by only concentrating on voltage form is expressed as follows:

$$
V_{\mathrm{SA}}(u) \times F(u)=X(u),
$$

where $F(u)$ is the normalized input of the SA and $X(u)$ is the normalized desired output function. The normalized input is obtained using inverse dynamic by substituting the SA sawtooth function and the desired output form in (17).

3.2. Desired Output Behavior. The function representing the point-to-point output characteristic should be differentiable and continuous at least up to a second order derivative at which the first derivative and the second derivatives at initial and final simulation time points, $X_{E}$, are zero and remain zero. According to [18], asymptotic behavior is desired when the final position is reached to remain in the same position and the use of exponential functions introduced by [8] is one of the most efficient solutions. Here, the third order exponential function of the output function is evaluated to control the system from time $=0$ to $X_{E}$ as the target output waveform is similar to the first derivative of this exponential function (Table 4). This third order exponential function is expressed as follows:

$$
x(t)=X_{E}\left[1-e^{-(\alpha t)^{3}}\right] .
$$

To generalize the analysis, we can define the normalized time $u$ as follows:

$$
u=\alpha t \text {. }
$$

From (18) and (19), the normalized equation of the desired output function is derived as follows:

$$
X(u)=\frac{x(t)}{X_{E}}=1-e^{-u^{3}} .
$$

The derivatives are shown in the following equations:

$$
\begin{gathered}
\dot{X}(u)=\frac{1}{\alpha X_{E}} \dot{x}(t)=-e^{-u^{3}} \frac{d}{d u}\left(-u^{3}\right)=3 u^{2} e^{-u^{3}}, \\
\ddot{X}(u)=\frac{1}{\alpha^{2} X_{E}} \ddot{x}(t)=3\left[u^{2} \frac{d}{d u}\left(e^{-u^{3}}\right)+e^{-u^{3}} \frac{d}{d u}\left(u^{2}\right)\right] \\
=\left(6 u-9 u^{4}\right) e^{-u^{3}} .
\end{gathered}
$$




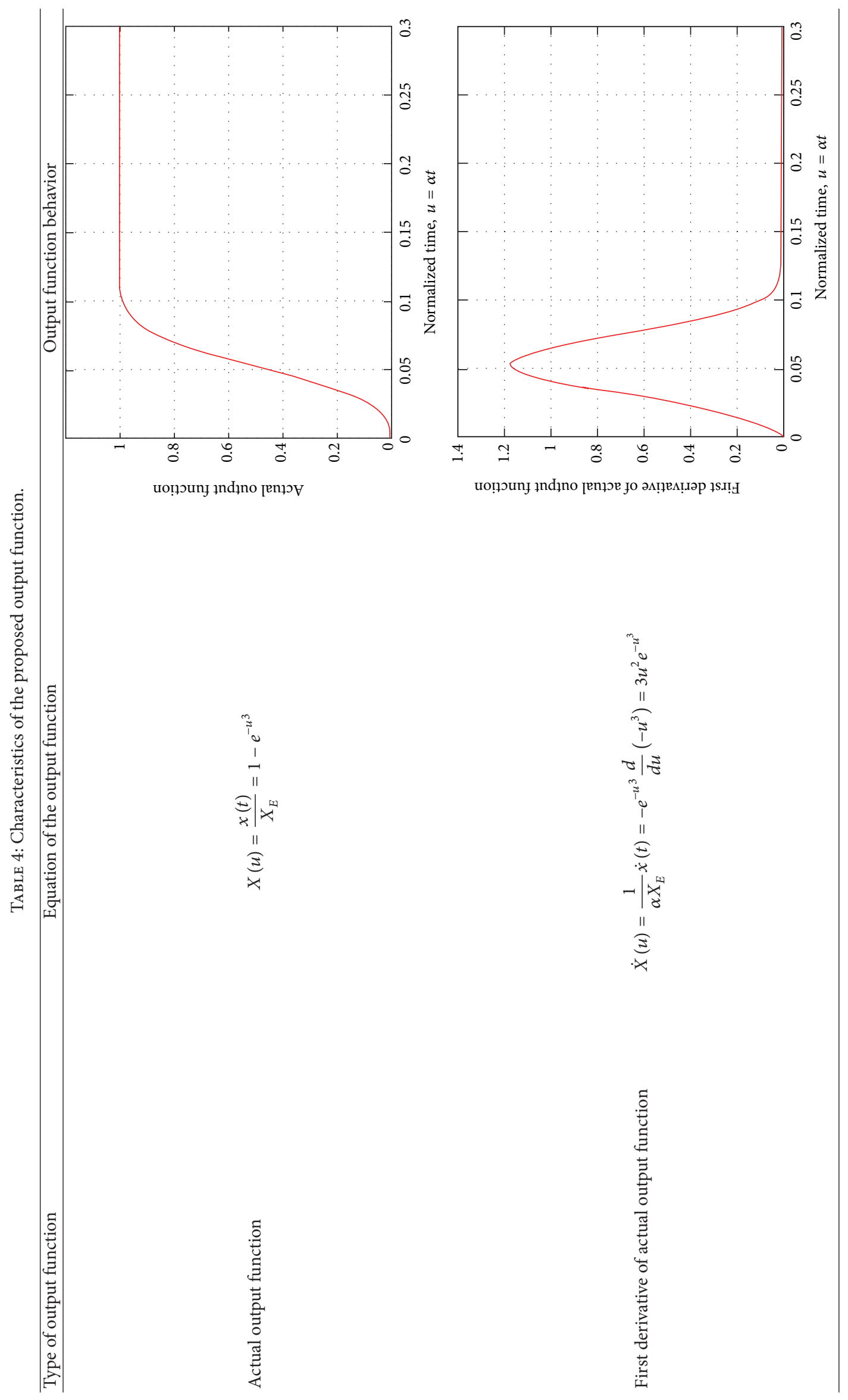




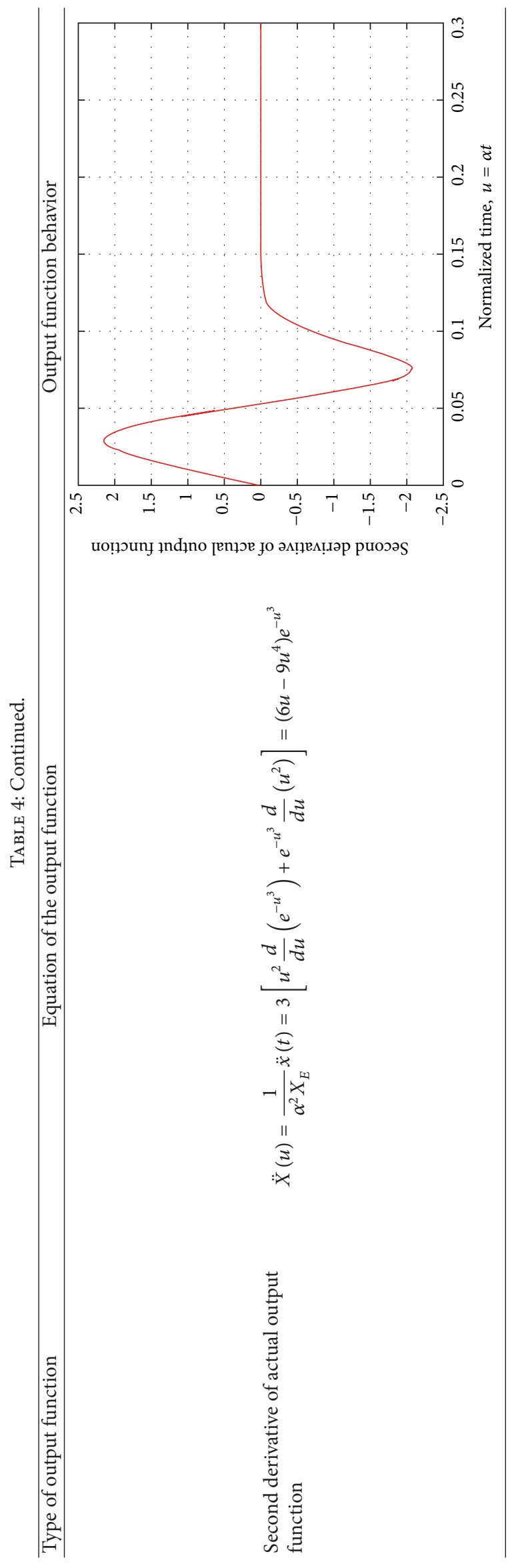




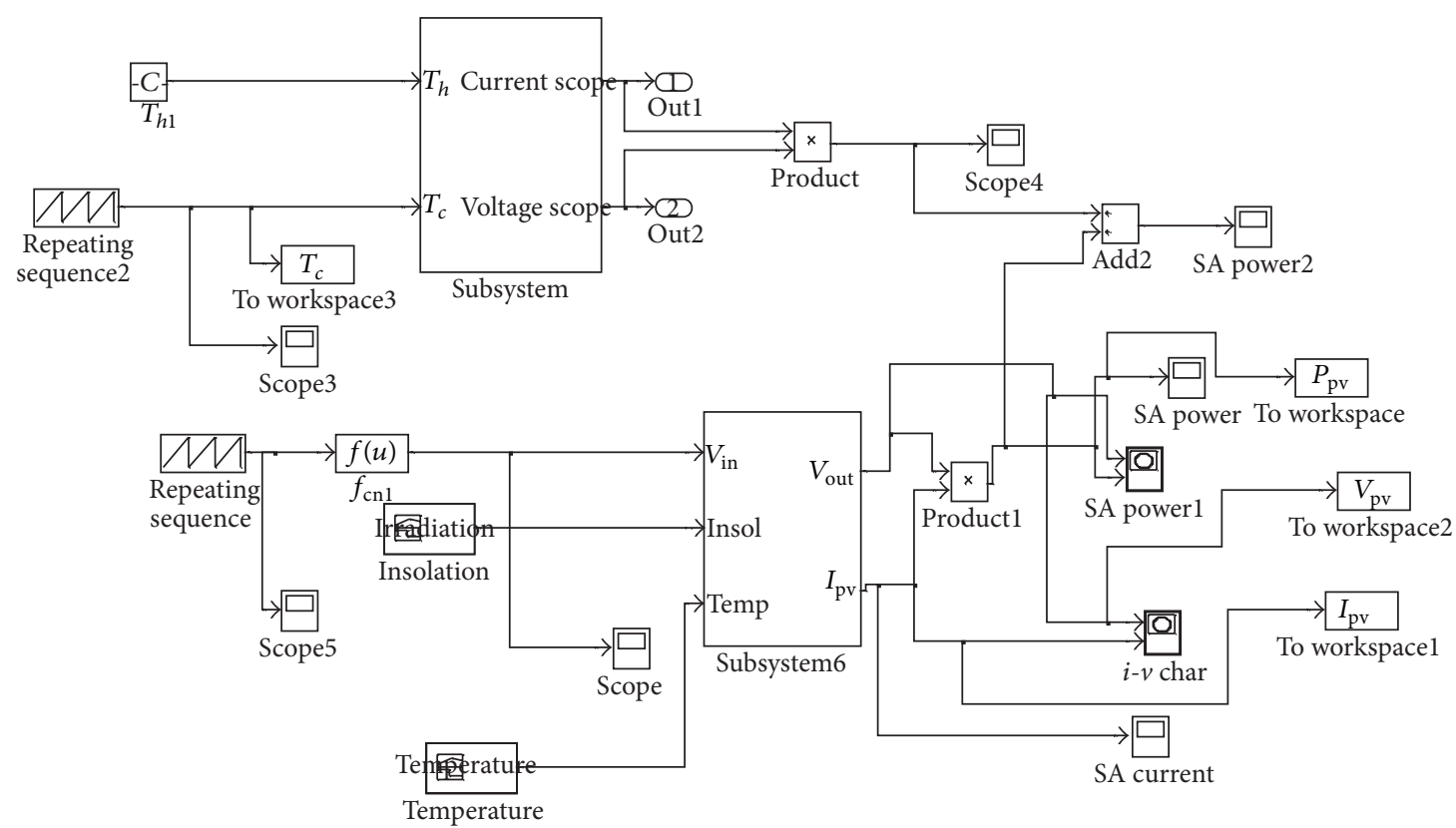

FIgURE 4: Thermoelectric-solar hybrid energy system block model applied in MATLAB.

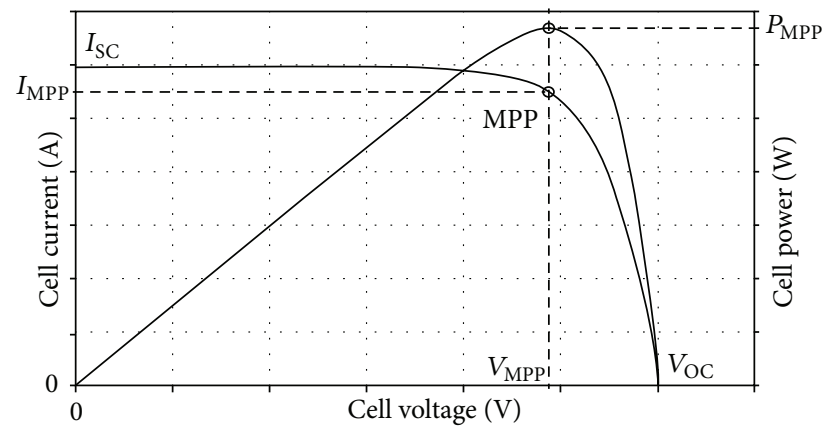

Figure 5: $I-V$ and $P-V$ characteristics of a solar cell [29].

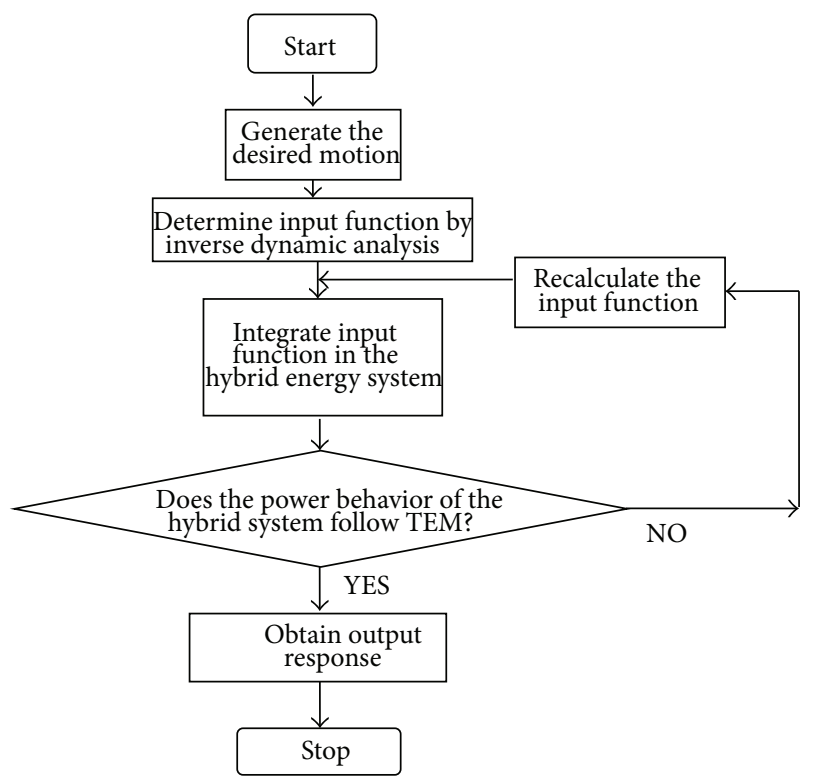

FIGURE 6: Design process of the inverse dynamic analysis.

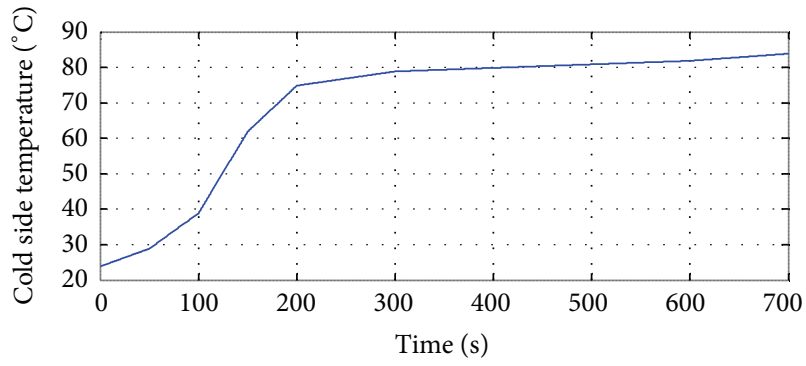

Figure 7: Temperature variation in the cold side of TEM.

Table 4 shows the characteristics of the proposed output function defined by the actual output function as well as the first and second derivatives of the actual output functions. As the desired output voltage function of the SA is the same as the first derivative of the third order exponential function, $X(u)$ is set to be

$$
X(u)=\dot{X}(u)=3 u^{2} e^{-u^{3}}
$$

3.3. Exponential Input Shaping Design. The input function corresponds to the input voltage, which initially increases proportionally with time to the exponential behavior. As such, the input function is calculated to be

$$
\begin{aligned}
& F(u)=\frac{\left(3 u^{2}\right) e^{-u^{3}}}{V_{\mathrm{SA}}(u)}, \\
& F(u)=\frac{\left(3 u^{2}\right) e^{-u^{3}}}{A \operatorname{frac}(u / T+\phi)},
\end{aligned}
$$

where $A=30 \mathrm{~V}, T=10 \mathrm{~s}$, and $\phi=0^{\circ}$. 


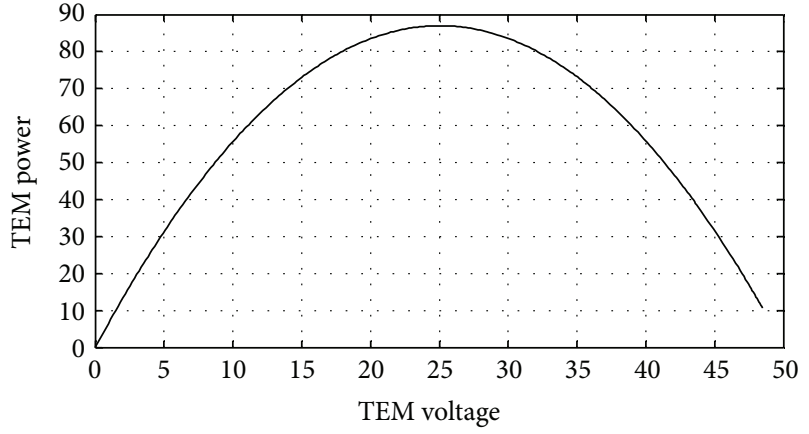

(a)

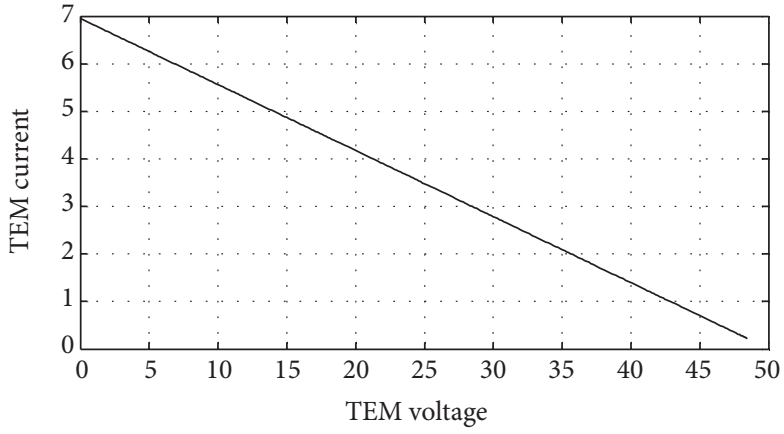

(b)

Figure 8: TEM characteristics at a temperature variation from $25^{\circ} \mathrm{C}$ to $85^{\circ} \mathrm{C}$ : (a) $P-V$ characteristic and (b) $I-V$ characteristic.

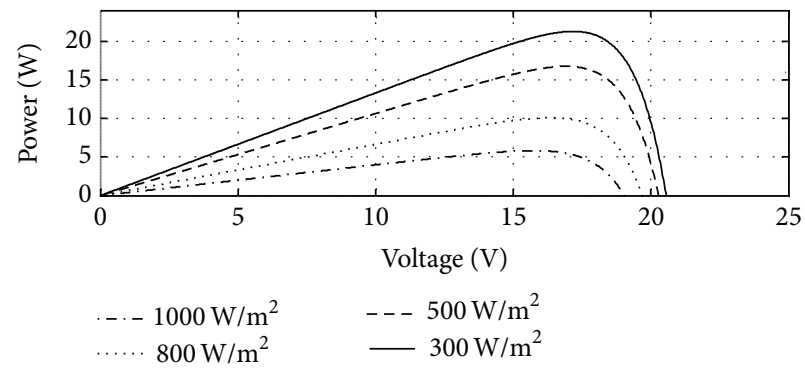

(a)

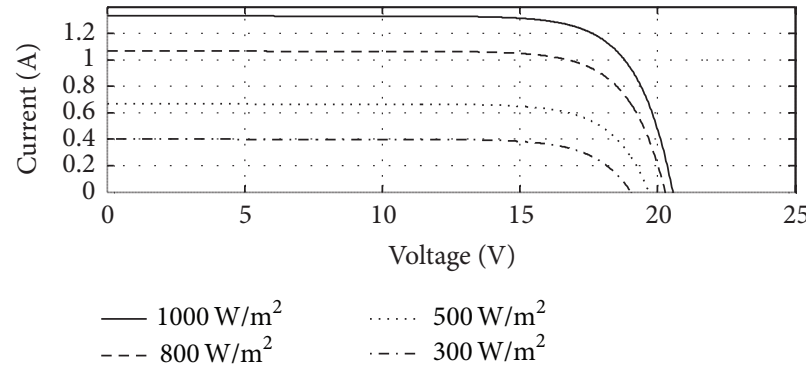

(b)

FIgURE 9: SA characteristics at different insolation: (a) $P-V$ characteristic and (b) $I-V$ characteristic.

The new output power is determined to be the same behavior as the input voltage. As a result, the total hybrid power tracks the TEM behavior because the SA power behavior is changed by the new input signal. Figure 6 shows the design process of inverse dynamic analysis.

\section{Simulation Results}

Two simulation models are designed using MATLAB: one model is the hybrid system with an input shaper and the other model does not have an input shaper. From the standpoint of the TEM application, the maximum output power is desired, in which load resistance is set at the same value as internal resistance. The behavior of the individual system is plotted to configure mathematical modeling and the characteristic of output performance. For TEM, the low temperature data from a previous study [4] is used in the dynamic analysis of the TEM block at a constant high temperature of $115^{\circ} \mathrm{C}$. The variation in the low temperature is shown in Figure 7. The low temperature is gradually increased from $25^{\circ} \mathrm{C}$ to $75^{\circ} \mathrm{C}$ and maintained at that value until the end of simulation time.

The characteristic of TEM, in which six thermoelectric generators are connected in series, is shown in Figure 8. As TEGs are cascaded, single TEG voltages are combined and expressed as follows:

$$
V_{i}=i \times V,
$$

where $i$ is the number of cascaded thermoelectric generators. Considering that power is directly proportional to voltage, we can express total power as the maximum power of single TEG multiplied by the factor of $i$. In Figure 8, the total power is $87.6 \mathrm{~W}$ at the matched load current of $3.4 \mathrm{~A}$ and the matched load voltage of $25.2 \mathrm{~V}$.

For the SA block, the surface temperature is maintained at $40^{\circ} \mathrm{C}$ and simulation is conducted by varying insolation at $300,500,800$, and $1000 \mathrm{~W} / \mathrm{m}^{2}$. The $P-V$ and $I-V$ characteristics of SA are shown in Figure 9.

We compared the characteristics to verify the design by adding the input shaper to the input of SA and to the other one without the input shaper. After the input shaper was added, the input voltage of SA changed to the first derivative of exponential behavior (Figure 10).

For the next analysis, the SA voltage curve is changed to different curvature to see the effect after adding the same input shaper as the previous analysis. It is notable by comparing Figures 10 and 11 that the characteristic of the SA voltage with input shaper is the same regardless of the given curve of the initial SA voltage. The curve shows its peak value is $1.18 \mathrm{~V}$ at time $0.88 \mathrm{~s}$ for both cases. This is the beauty of this exponential input shaper in view of the fact that it is able to maintain and stabilize any form of curve according to its exponential characteristic.

The performance of the hybrid energy system with the input shaper is observed by varying the input of TEM as the SA branch is fixed at $1000 \mathrm{~W} / \mathrm{m}^{2}$. The temperature of the 


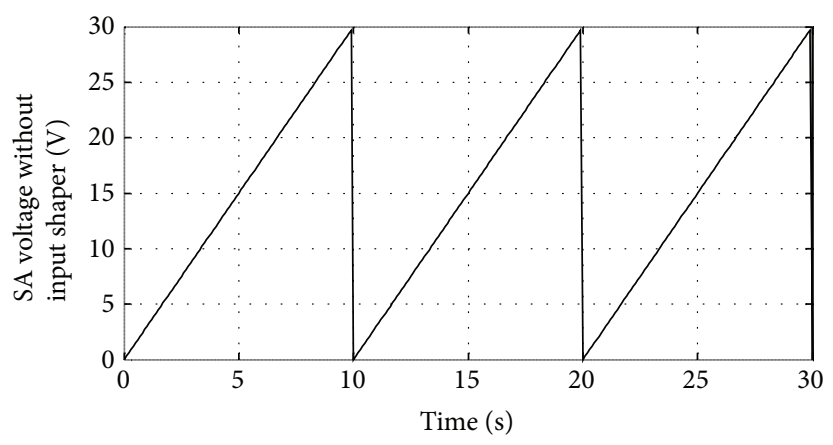

(a)

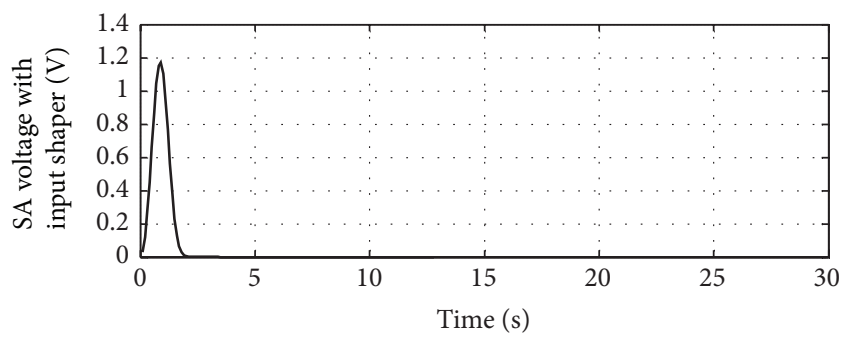

(b)

FIgURE 10: Case 1: SA voltage (a) without and (b) with input shaper.

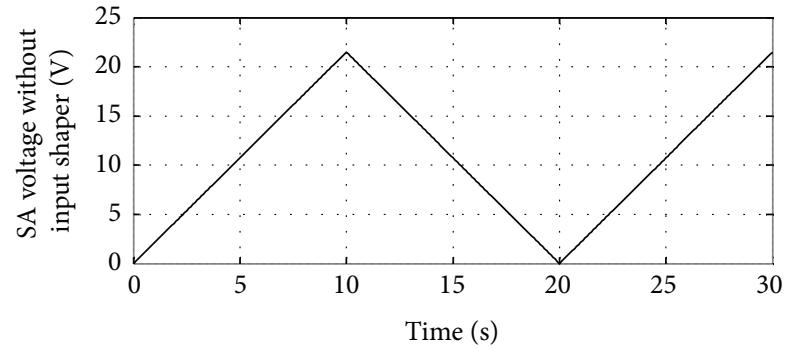

(a)

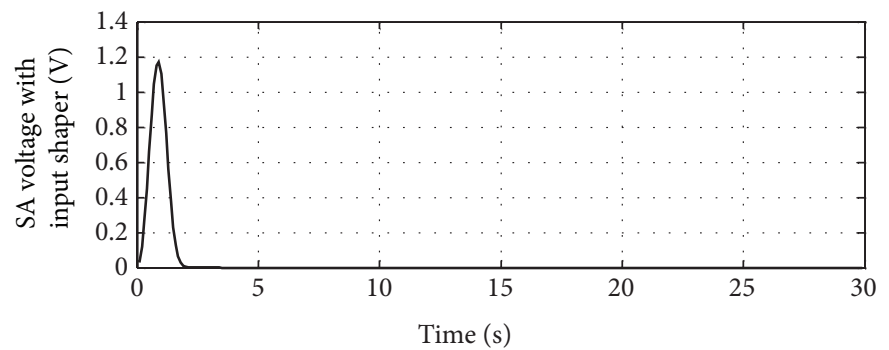

(b)

FIgURE 11: Case 2: SA voltage (a) without and (b) with input shaper.

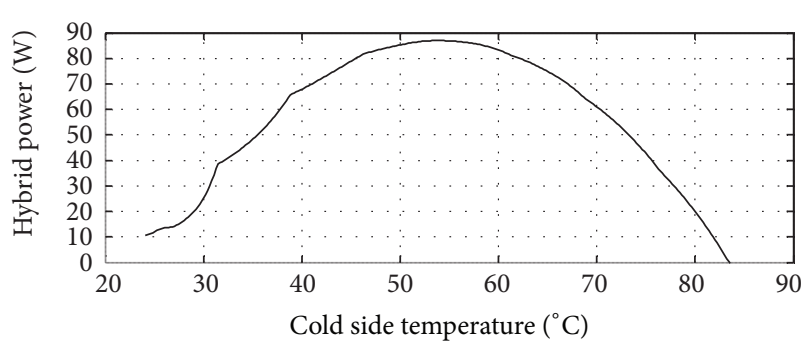

FIGURE 12: Total hybrid power.

cold side of TEM is varied from $25^{\circ} \mathrm{C}$ to $85^{\circ} \mathrm{C}$ as observed in the power curve in Figure 12. The result shows that the overall output power corresponds to the TEM behavior by only controlling the SA part.

To summarize this method, we present the comparison results of the performance of the individual system and the hybrid system with and without the input shaper in Figure 13.

Figure 13 shows that the inverse dynamic analysis can control the output behavior of SA to follow the TEM behavior under a transient operating condition. It is worth stressing that the following remarks can be concluded from Figures 713.

(1) This finding is one of the most important factors that should be considered before any MPPT circuit is designed for this hybrid system. This observation is considered because the time constant of SA is less than that of TEM. SA is also established to imitate the TEM behavior. Hence, an appropriate behavior of the output power curve is initially developed to falsify the acquired overall output behavior of the hybrid system.

(2) The extra recognition of the inverse dynamic analysis involves a user that selects the optimum overall system behavior; this behavior is chosen to induce the designed input function to respond to the selected output function. This procedure can be conducted to reduce hardware pricing by not designing the separate controller for both systems before a hybrid system is formed. For this reason, this hybrid system can be used to estimate the MMP of the overall system by using a single controller to regulate both systems.

(3) In contrast to the method presented in a previous study [5], the proposed method can reduce the power consumption of this hybrid system without using any digital controller and achieve the desired output power curve.

(4) This system also reduces the bare bones of designing the MPPT for different systems before such bones are combined to form a hybrid system.

(5) By comparing with the existing works, it can be seen from Figure 10(b) that the SA voltage with the proposed input shaper follows the same characteristics of the similar input shaper applied to flexible system in [8]. This proposed method is able to stabilize the hybrid system to certain condition which 


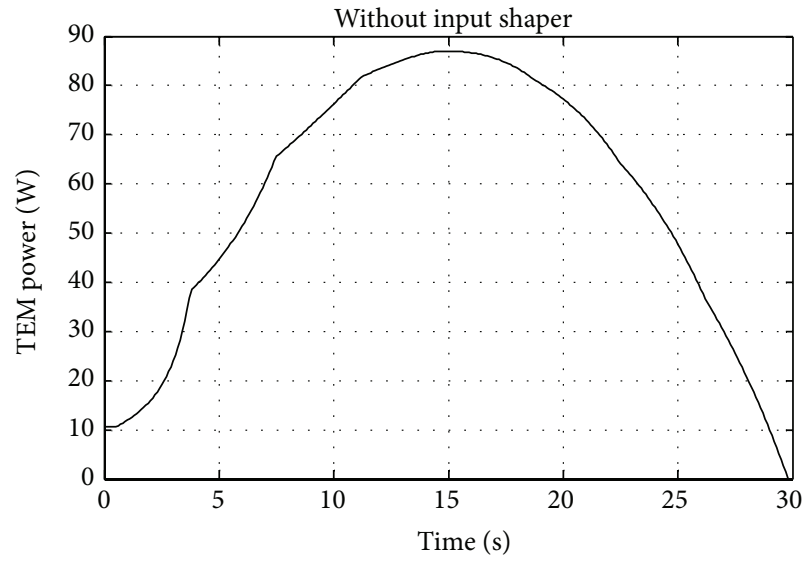

(a)

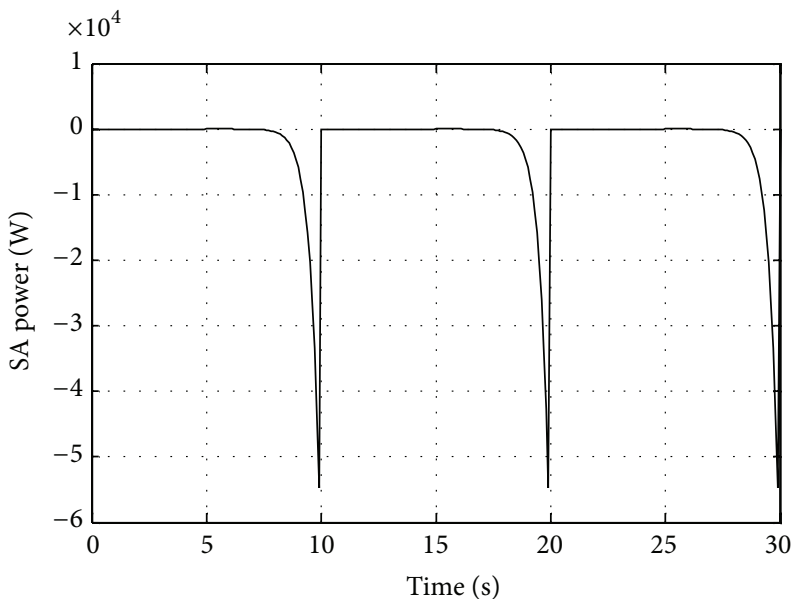

(c)

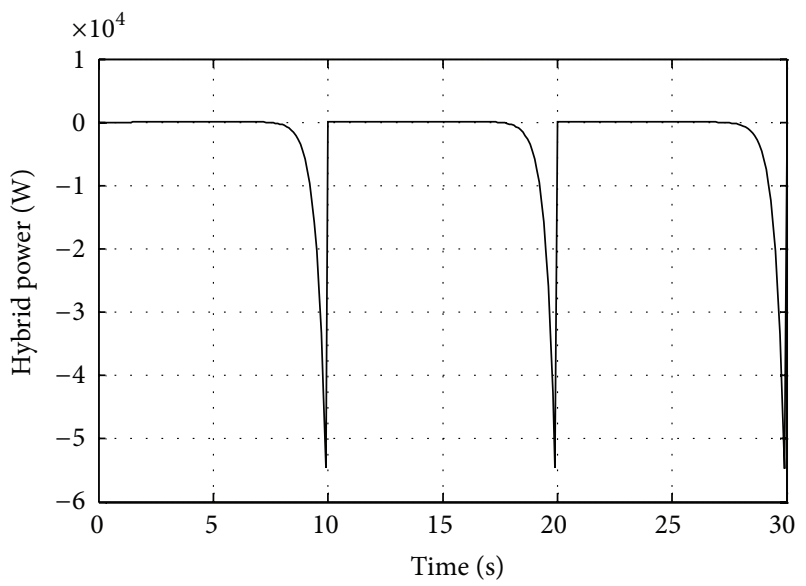

(e)

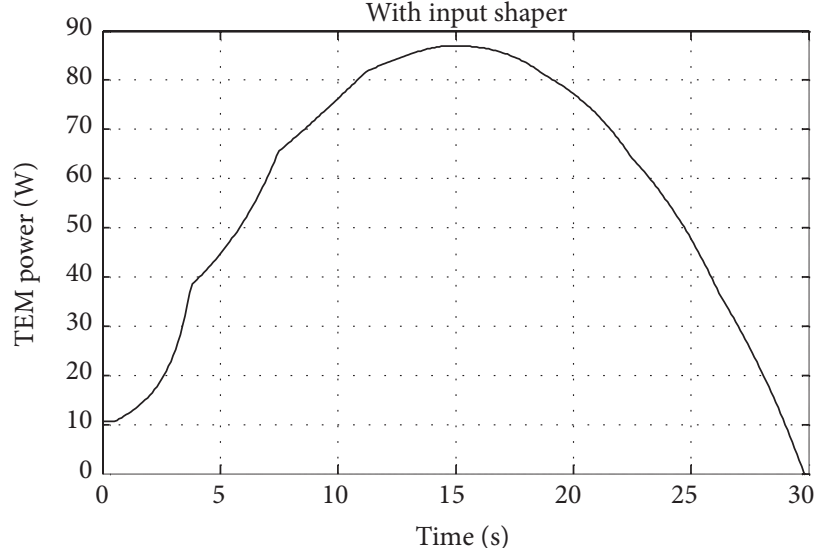

(b)

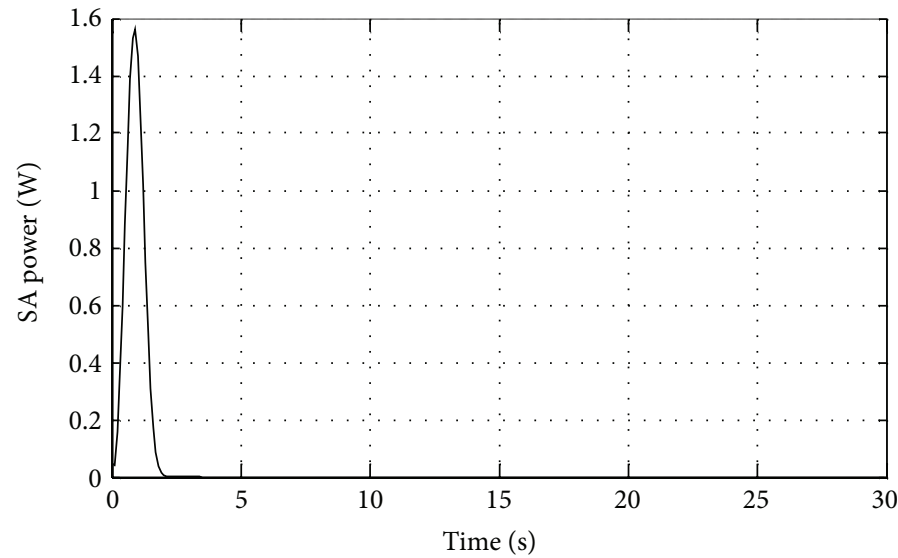

(d)

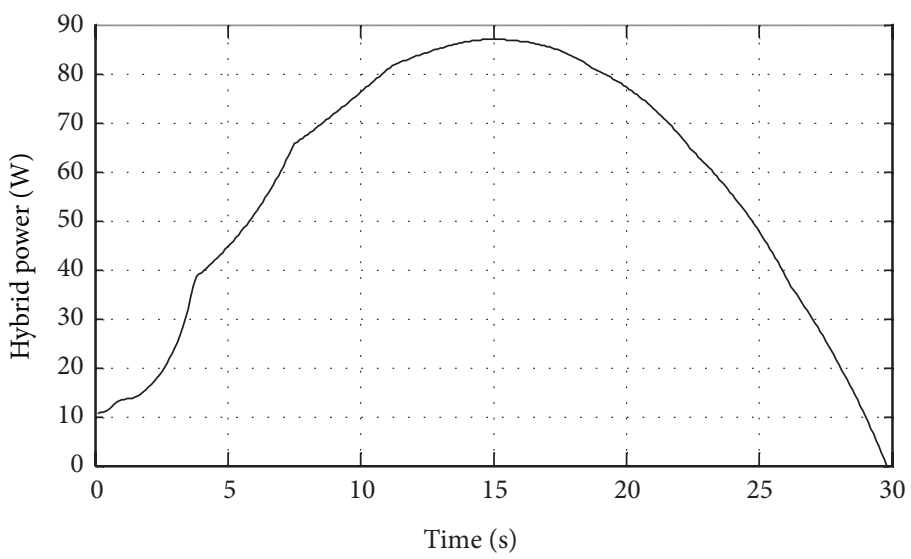

(f)

FIgURE 13: Power curve comparison.

is to follow the characteristic of the TEM. From this observation, the exponential function input shaper is capable of obtaining the same characteristic in the application of energy systems although the system is different since previously it was solitude to the application of flexible systems.

(6) Again, from Figure 10(b), the peak value of the SA voltage is close to $1.18 \mathrm{~V}$ at the normalized time of 
$0.88 \mathrm{~s}$. The same characteristic is drawn from [8] where the different systems are looking on.

The effectiveness of the exponential function input shaper when applied to the hybrid energy system of TEM-SA is convincible to work very well since the output power curve needs to be stabilized to certain value before MPPT circuit is designed. The stability factor is one of the main parameters that will be stressed out after the MPPT is designed for this hybrid energy system.

\section{Conclusion}

A formulation of the TEM-SA behavior, which includes thermal behavior and electrical properties, has been developed using MATLAB/SIMULINK. This model is used to determine the output power characteristics of TEM, SA, and hybrid energy system for transient analysis. Simulation results show that an inverse dynamic analysis based on exponential function can be applied to control the output behavior of the SA. The satisfactory curve of the hybrid output power is achieved using this method. In addition, this method simplifies the control of the overall system, in which the controller is only designed to control the SA output behavior, such that SA behavior follows the TEM characteristic. The controlled input behavior is applied to further minimize the energy consumption of the system. Significant efforts have been devoted to the development of this input shaper. In this system, the input shaper is designed according to the acquired output behavior of the hybrid energy system. In addition, the inverse dynamic type input shaper can be built by using built-in control blocks, which can be combined further using SimPowerSystem tools to develop the MPPT circuit. The MPPT circuit can then be applied in the hybrid system to obtain the MPP and generate electricity for electronic device applications. Considering that the overall output behavior follows the TEM behavior, we recommend that only one MPPT circuit should be designed for this hybrid system.

\section{Conflict of Interests}

The authors declare that there is no conflict of interests regarding the publication of this paper.

\section{Acknowledgments}

The authors would like to thank the Department of Electrical, Electronic and Systems Engineering, Faculty of Engineering and Built Environment, Universiti Kebangsaan Malaysia (UKM), the Universiti Teknikal Malaysia Melaka (UTeM), and the Ministry of Higher Education for moral, operational, and financial support for this project.

\section{References}

[1] N. Smith and R. McCann, "Investigation of a multiple input converter for grid connected thermoelectric-photovoltaic hybrid system," in Proceedings of the IEEE Green Technologies Conference, April 2012.

[2] A. R. Jha, Solar Cell Technology and Applications, CRC Press, 2009.

[3] S. Odeh and M. Behnia, "Improving photovoltaic module efficiency using water cooling," Heat Transfer Engineering, vol. 30, no. 6, pp. 499-505, 2009.

[4] N. Q. Nguyen and K. V. Pochiraju, "Behavior of thermoelectric generators exposed to transient heat sources," Applied Thermal Engineering, vol. 51, no. 1-2, pp. 1-9, 2013.

[5] X. Zhang and K. T. Chau, "Design and implementation of a new thermoelectric-photovoltaic hybrid energy system for hybrid electric vehicles," Electric Power Components and Systems, vol. 39, no. 6, pp. 511-525, 2011.

[6] M. M. M. Daud, N. B. M. Nor, and T. Ibrahim, "Novel hybrid photovoltaic and thermoelectric panel," in Proceedings of the IEEE International Power Engineering and Optimization Conference (PEOCO '12), pp. 269-274, Melaka, Malaysia, June 2012.

[7] D. Yang and H. Yin, "Energy conversion efficiency of a novel hybrid solar system for photovoltaic, thermoelectric, and heat utilization," IEEE Transactions on Energy Conversion, vol. 26, no. 2, pp. 662-670, 2011.

[8] M. N. Sahinkaya, "Input shaping for vibration-free positioning of flexible systems," Proceedings of the Institution of Mechanical Engineers: Journal of Systems and Control Engineering, vol. 215, no. 5, pp. 467-481, 2001.

[9] M. N. Sahinkaya, "Inverse dynamic analysis of multiphysics systems," Proceedings of the Institution of Mechanical Engineers: Journal of Systems and Control Engineering, vol. 218, no. 1, pp. 13-26, 2004.

[10] S. Devasia, "Time-optimal control with pre/post actuation for dual-stage systems," IEEE Transactions on Control Systems Technology, vol. 20, no. 2, pp. 323-334, 2012.

[11] P. Häuptle, P. Hubinský, and G. Gruhler, "Harmonic modulated feedback in control to lower oscillations in mechatronic systems," in Proceedings of the 11th International Conference on Control, Automation and Systems (ICCAS '11), pp. 273-276, IEEE, October 2011.

[12] M. Rahimi and M. B. Ghaznavi-Ghoushchi, "Improvement of timing specifications in second order electronic systems using programmable CMOS Posicast pulse shapers," in Proceedings of the 20th Iranian Conference on Electrical Engineering (ICEE '12), pp. 309-313, May 2012.

[13] S. Garrido, M. Abderrahim, A. Giménez, R. Diez, and C. Balaguer, "Anti-swinging input shaping control of an automatic construction crane," IEEE Transactions on Automation Science and Engineering, vol. 5, no. 3, pp. 549-557, 2008.

[14] J. R. Huey and W. Singhose, "Design of proportional-derivative feedback and input shaping for control of inertia plants," IET Control Theory \& Applications, vol. 6, no. 3, pp. 357-364, 2012.

[15] C. La-orpacharapan and L. Y. Pao, "Fast and robust control of systems with multiple flexible modes," IEEE/ASME Transactions on Mechatronics, vol. 10, no. 5, pp. 521-534, 2005.

[16] W. E. Singhose, L. J. Porter, T. D. Tuttle, and N. C. Singer, "Vibration reduction using multi-hump input shapers," Journal of Dynamic Systems, Measurement and Control, Transactions of the ASME, vol. 119, no. 2, pp. 320-326, 1997. 
[17] S. S. Gürleyük, Ö. Bahadir, Y. Türkkan, and H. Üsenti, "Improved three-step input shaping control of crane system," WSEAS Transactions on Systems, vol. 7, no. 6, pp. 652-661, 2008.

[18] A. Piazzi and A. Visioli, "Minimum-time system-inversionbased motion planning for residual vibration reduction," IEEE/ASME Transactions on Mechatronics, vol. 5, no. 1, pp. 1222, 2000.

[19] P. Iravani and M. N. Sahinkaya, "Variable-velocity exponential input shaping for position controlled robotic systems," in Proceedings of the 3rd Annual Dynamic Systems and Control Conference (DSCC '10), pp. 345-351, University of Bath, September 2010.

[20] X. Zhao, L. Zhang, and P. Shi, "Stability of a class of switched positive linear time-delay systems," International Journal of Robust and Nonlinear Control, vol. 23, no. 5, pp. 578-589, 2013.

[21] X. Zhao, X. Liu, S. Yin, and H. Li, "Improved results on stability of continuous-time switched positive linear systems," Automatica, vol. 50, no. 2, pp. 614-621, 2014.

[22] Z. Xudong, Z. Lixian, S. Peng, and H. R. Karimi, "Robust control of continuous-time systems with state-dependent uncertainties and its application to electronic circuits," IEEE Transactions on Industrial Electronics, vol. 61, no. 8, pp. 4161-4170, 2014.

[23] R. Guo, P. Zhao, and C. Zhang, "Input-to-state stability for a class of switched stochastic nonlinear systems by an improved average dwell time method," Mathematical Problems in Engineering, vol. 2014, Article ID 154679, 8 pages, 2014.

[24] M. S. Branicky, "Multiple Lyapunov functions and other analysis tools for switched and hybrid systems," IEEE Transactions on Automatic Control, vol. 43, no. 4, pp. 475-482, 1998.

[25] W. Ni, D. Cheng, and X. Hu, "Minimum dwell time for stability and stabilization of switched linear systems," in Proceedings of the 7th World Congress on Intelligent Control and Automation (WCICA '08), pp. 4103-4108, IEEE, June 2008.

[26] Z. Rymansaib, P. Iravani, and M. N. Sahinkaya, "Exponential trajectory generation for point to point motions," in Proceedings of the IEEE/ASME International Conference on Advanced Intelligent Mechatronics (AIM '13), 2013.

[27] H.-L. Tsai and J.-M. Lin, "Model building and simulation of thermoelectric module using Matlab/Simulink," Journal of Electronic Materials, vol. 39, no. 9, pp. 2105-2111, 2010.

[28] N. Pandiarajan, R. Ramaprabha, and R. Muthu, "Application of circuit model for photovoltaic energy conversion system," International Journal of Photoenergy, vol. 2012, Article ID 410401, 14 pages, 2012.

[29] S.S. Mohammed, "Modeling and simulation of photovoltaic module using MATLAB/Simulink," International Journal of Chemical and Environmental Engineering, vol. 2, no. 5, pp. 350355, 2011.

[30] E. W. Weisstein, "Fourier Series-Sawtooth Wave," MathWorld-A Wolfram Web Resource, 1999, http://mathworld.wolfram.com/FourierSeriesSawtoothWave.html.

[31] H.-L. Tsai, C.-S. Tu, and Y.-J. Su, "Development of generalized photovoltaic model using MATLAB/SIMULINK," in Proceedings of the World Congress on Engineering and Computer Science, 2008 . 

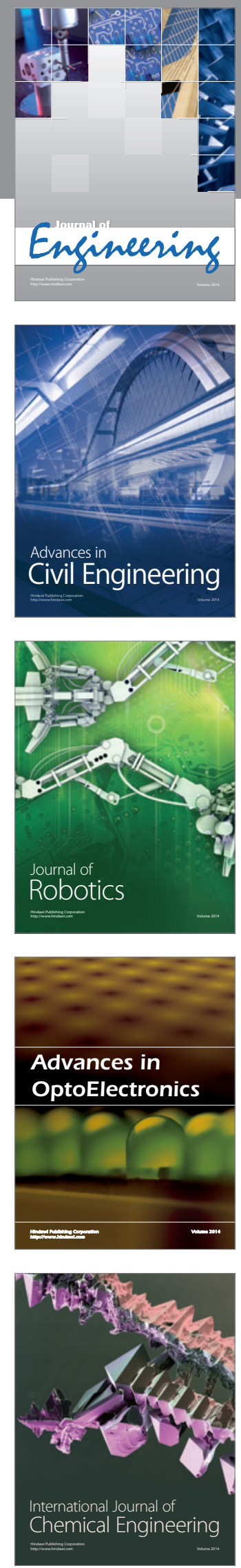

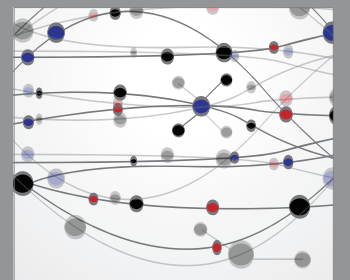

The Scientific World Journal
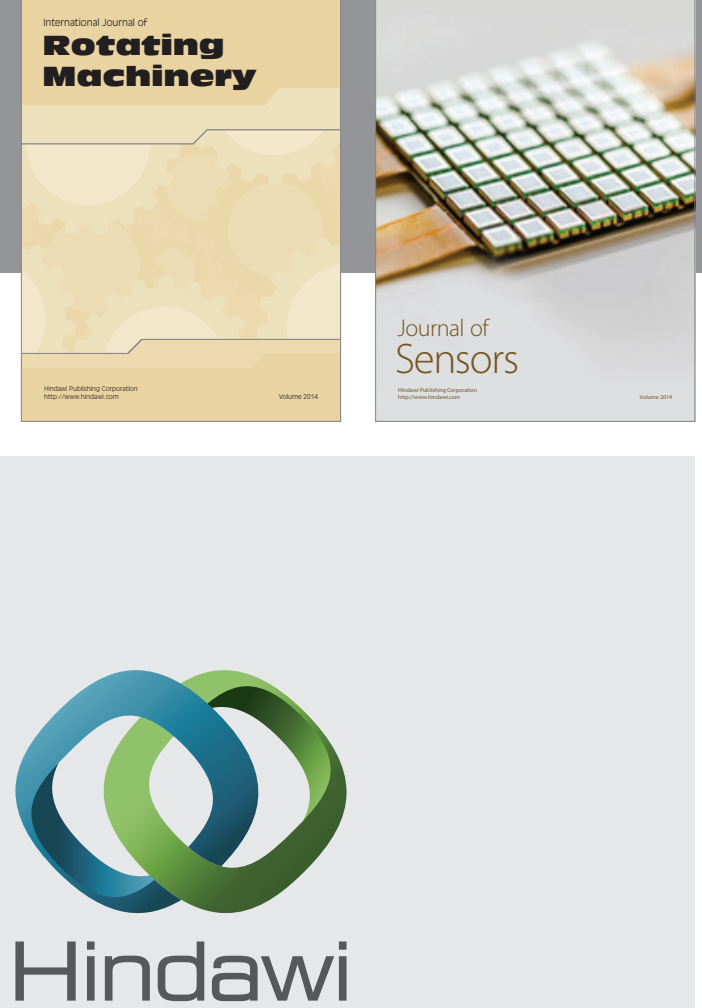

Submit your manuscripts at http://www.hindawi.com
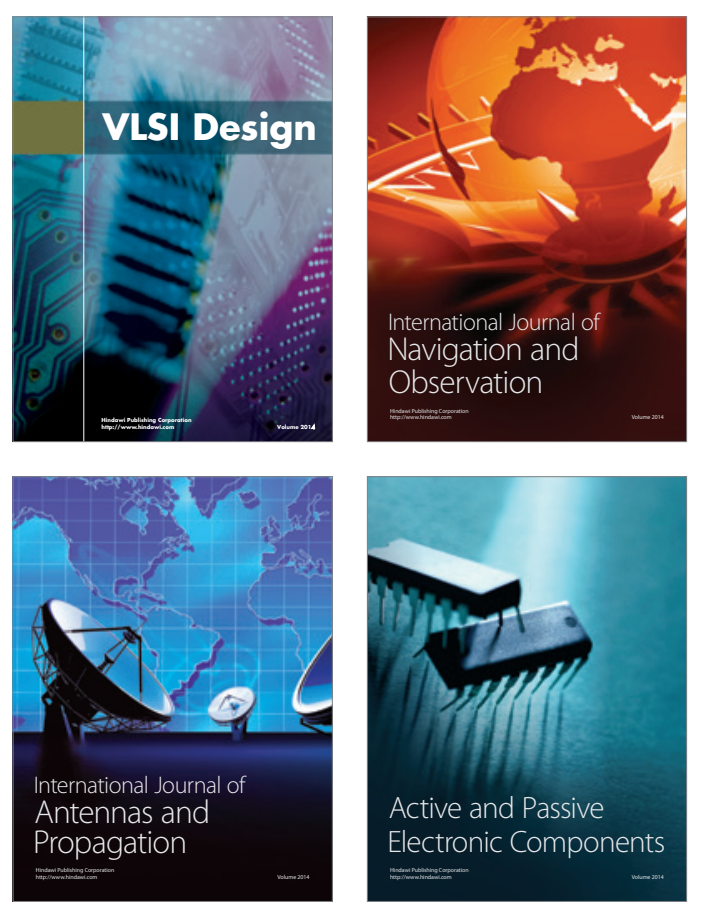
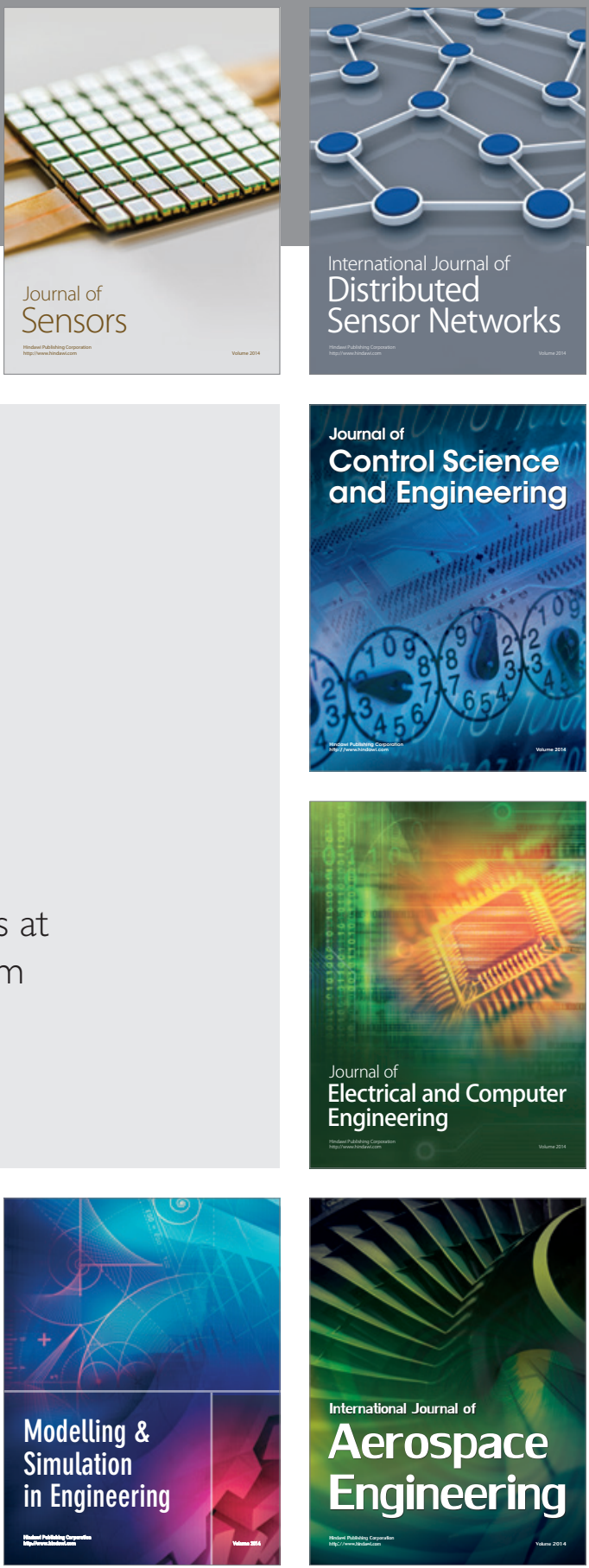

Journal of

Control Science

and Engineering
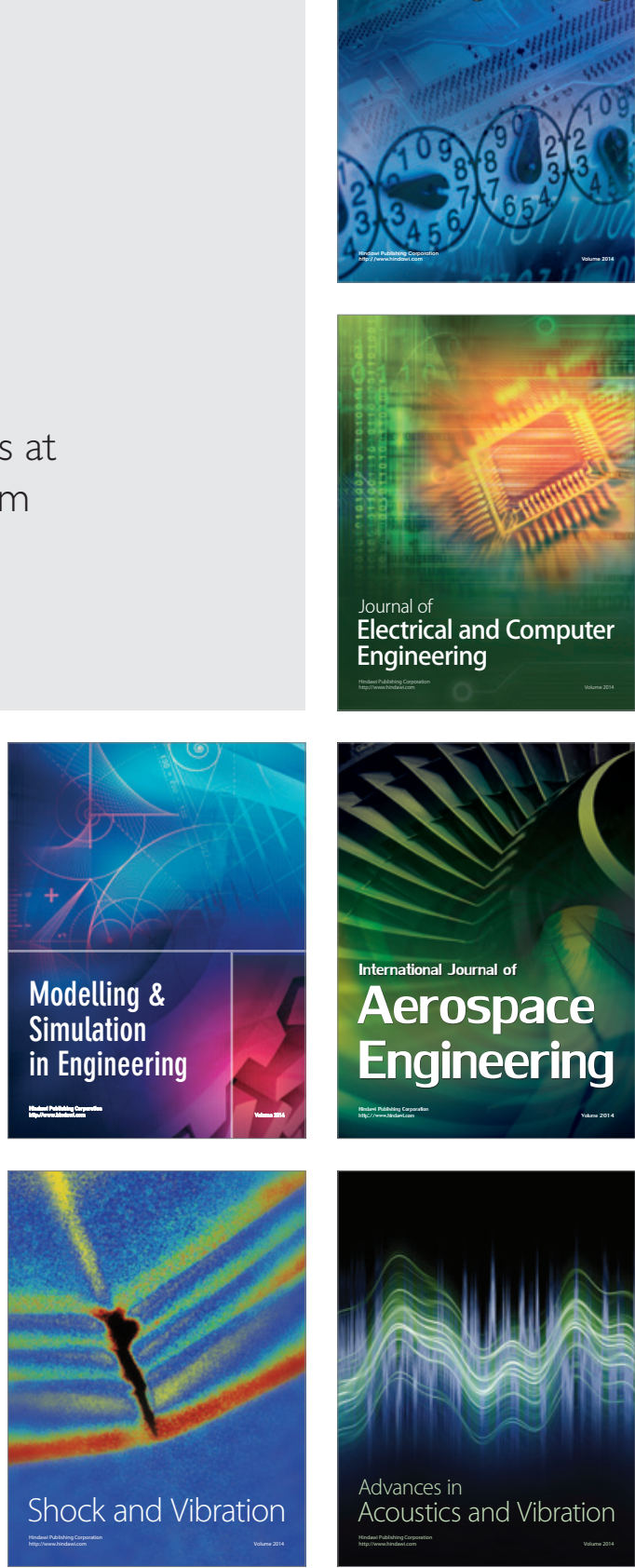